\title{
Listening to Prozac
}

SIR - Listening to Prozac by Peter D. Kramer is certainly a very bad book, but it deserved a better informed review than that from Charles Medawar (Nature 368 , $369 ; 1994)$. It is impossible to deal here with his entire shoal of red herrings, but several points need to be made.

Prozac is one of five drugs (selective serotonin re-uptake inhibitors, or SSRls) with the same basic action that are in widespread clinical use; its only major difference from the others is that its effects last longer. This may be advantageous or not for different people, but makes little practical difference in most cases. If Prozac were 'addictive', the same would have to be true of the other SSRIs, but no-one has suggested that this is so.

During the past 35 years, there has in fact been no evidence that any antidepressants - whatever their structure cause 'addiction' or 'dependence'. Medawar says there is "profound confusion" over the meaning of these terms and, if so, he has certainly added to it. Diabetics are 'dependent' on insulin and people with high blood pressure are dependent on hypotensives, in the sense that they will become ill again if they stop taking the drugs. Many sufferers from depression are in the same position, but this is totally different from the experience of people who take heroin or cocaine as euphoriants. They suffer from dose escalation and distress on stopping, not a return to a morbid state that existed before the drugs were first taken.

There is a fundamental difference between drugs that have a euphoriant effect for practically everyone (alcohol, heroin and so on) and those that improve the mood only of people suffering from a mood disorder. Whereas the first category acts almost immediately, the beneficial effect of antidepressants does not begin for about two weeks. People who are not depressed and who take antidepressants only experience side effects - a poor recommendation for a 'recreational' drug. Further, there is no evidence that Prozac (or any other antidepressant) affects personality, as opposed to disordered mood. Kramer's few anecdotal cases certainly provide no such evidence.

The usual dosage of Prozac has been well established for at least ten years at 20 $\mathrm{mg}$, although a range of doses is nothing unusual in pharmacology and there have been recent reports that some patients respond well to less than $20 \mathrm{mg}$. Every drug has some unwanted side effects, but the safety profile of Prozac is advantageous. Any drug can be misused, but this is no reason to deprive people of its benefits.

Effective drugs that have been shown to have no potential for addiction exist for the treatment of anxiety - buspirone and the monoamine-oxidase inhibitors. Far from antidepressants being excessively used, all the available evidence shows that many more people could be relieved of unnecessary suffering by the more effective use of these drugs. It would be regrettable if serious depressive illness, often involving the risk of suicide, remained untreated through people being misinformed about the well-established properties of antidepressants.

\section{Hugh Freeman}

\section{Montagu Square.}

London W1H 1RE, UK

SIR - Medawar is largely right in his criticisms of Listening to Prozac; in claiming that Prozac - and other antidepressants - is potentially addictive, he is not only wrong, but doubly so.

First he has confused antidepressants and antipsychotic drugs with two other classes of drug: sedatives and stimulants, such as Valium and cocaine. Not only have the former drugs been around for longer than the benzodiazepines, but any clinician knows of the difficulties of getting unwell patients to stay on them, to say little of well ones - hardly suggestive of addictive potential.

The fact that the media claim that many hundreds of people are prescribed Prozac signifies little more than the exaggeration of an anecdote for a good story. Any patient who is put unnecessarily on Prozac will invariably discontinue it within a few weeks, either out of boredom or owing to side effects (and yes, they do occur, even with Prozac). Just ask any psychiatrist in clinical practice.

What makes a drug addictive is the production of feelings of elation, euphoria or ease; growing tolerance and loss of effects over time; and withdrawal symptoms when the drug is stopped. Although antidepressants may have a few mild 'rebound' symptoms on discontinuation, this cannot be equated with dependence. Furthermore, the reason they are sometimes slowly discontinued ("phased withdrawal') is to minimize the likelihood of convulsions, an occasional but unrelated issue

In denying the beneficial effects of a new and easily tolerable antidepressant, Medawar seems preoccupied with the likelihood of addiction. What then does he have to say about the fact that even tap water can be addictive (psychogenic polydipsia)? The real axe he has to grind is an anti-psychiatry and anti-doctor one; he should at least have the grace to come out and say so.

\section{Robert Kaplan}

The Liaison Clinic, PO Box 5222 ,

Wollongong NSW 2500, Australia
SIR - Kramer is clearly fascinated scientifically by the effects of psychoactive drugs on personality, and deeply concerned about the moral and ethical dimensions of what one might call 'personality engineering'. So I am mystified why Medawar calls him "alarmingly disingenuous" for raising these issues publicly and accuses him of seeking to "stimulate mass demand" for the drug.

Medawar also criticizes Kramer for using too many anecdotes about his patients. As observation of patients would seem to be indispensable for a clinician trying to evaluate a drug's effect, I am hard-pressed to understand how one could write about the effects of Prozac without using anecdotes. Does Medawar accept only statements about mortality rates?

Medawar reasonably addresses the issue of whether Prozac may be addictive. I doubt whether he would deny insulin to a patient condemned to diabetes, but would he deny antidepressants to people suffering from another genetically linked disease, chronic depression? His tone "patients don't crave so long as doctors readily prescribe" - gives the impression that he considers prescription of psychoactive drugs to be the lazy doctor's approach, and ingestion of the drug a moral failing on the part of the patient.

I have for several years been in frequent (often daily) contact with someone who takes Prozac under the close supervision of a psychiatrist. This person, whose family history is rife with chronic depression, has achieved remarkable stability after a grim period of contemplating suicide. There seem to be no adverse side effects. I hope Medawar will pause to consider such anecdotes before trotting out his next denunciation.

Joseph Walder

2221 North East 41st Avenue,

Portland, Oregon 97221, USA

\section{Oh Canada!}

SIR - The fact that John Maddox was seduced by "majestic" Montreal in February (Nature 368, 389-394; 1994) is understandable to this native. Less understandable is his seduction by the separatist Parti Quebecois' rationales for secession of Quebec from Canada: Quebecois "feel differently in themselves when talking French" and "they want to live more intimately with people like themselves". Bah! This linguistic mawkishness conceals a hard-core jingoism that treats constitutional rights in the Canadian Charter as mere inconvenience. To see behind the front, read Mordecai Richler's Oh Canada! Oh Quebec! Requiem for a Divided Country (Penguin, 1992).

\section{Leonard Krishtalka}

Carnegie Museum of Natural History,

Pittsburgh, Pennsylvania 15213, USA 